\title{
Consideration factors in domestic investment for renewable energy development in Indonesia
}

\author{
Septi Riansyah* and Dony A. Chalid \\ Faculty of Economics and Business, Universitas Indonesia
}

\begin{abstract}
Development of renewable energy seen as one of the solutions when we talk about the climate change issue. Rapid growth and uncontrolled fossil fuel usage start to have an impact on world society. Renewable energy is a reliable solution to reduce further fossil fuel exploitation. This research is aiming to know consideration factors for domestic investors' decision to support the development of renewable energy in Indonesia as one of the funding beside FDI. Data gathered by the two-stage collection process - the first stage is in an expert interview to determining frameworks (AHP model) of factors related to domestic investment. The second stage is testing the framework using the AHP approach for each level in a pairwise comparison. This research showed that the domestic investors perceived access to the grid is crucial due to the market condition where government-owned companies fully control all power distribution. Getting the transparency on project clarity also critical for the independent power producers (IPP). By having it, the IPP can get a clear picture of the project requirement and provide the best proposal to the prospective investor. The last important factor is having Feed-in Tariff(FIT) pricing policy, which allowed guarantee fixed electricity prices. The IPP will be able to get financial return certainty and be relatively more comfortable forecasting their project cash flow.
\end{abstract}

Keywords: Renewable Energy, Domestic Investment, Independent Power Producers, Feed-in Tariff.

\section{Introduction}

One problem of developing renewable energy nowadays is the investor's perspective about the cost of initial investment to the project executed. Non-renewable energy, such as coal and petroleum, surprisingly requires more investment for resource explorations, which also giving risk for availability in long terms. The scarcity of supplies can also lead become a problem for the majority of the people. This situation will not happen for renewable energy as the fact showed Indonesia will always having advantages of its source of energy with a massive number of unexploited sources of energy from Solar Power, Hydropower, Wind Power, and Geothermal. However, the Renewable Energy development project initially seen to have higher initial costs (CAPEX) and relatively lower operating costs (OPEX). This

\footnotetext{
* Corresponding author: septiriansyah@gmail.com
} 
condition makes any development of a small, medium, and large project in developing renewable energy will need excellent support from long-term funding. Facts above usually occur in developing countries, where access for long-term funding is not easy to get for the newly established company. This fact is ironic since many sources of renewable energy are spread to developing countries with their natural resources. The most fundamental issue is that investors can see the economics of renewable energy as not competitive. Total production per unit of energy is higher compare with the total production cost of fossil fuels.

Lack of domestic investment readiness reflected in the year 2017 condition when the development of Renewable Energy in Indonesia is facing a hard challenge where many projects are trying to get funds by local financial institutions. Many IPP with new PPA contracts signed from 2017 are struggling to get finance from the lender, a majority in the project under ten megawatts (small capacity) - the kind of project that is not attractive for foreign direct investment. From this condition, we can see how critical the availability of domestic investment involvement in the development of a renewable energy project is in a developing country such as Indonesia.

This research aims to know any possible factors considered by domestic investors to support the development of renewable energy in Indonesia as one of the funding besides FDI. Data gathered by two-stage collection processes - the first stage in an expert interview to determined frameworks (AHP model) of factors related to domestic investment while the second stage is the frameworks testing using the AHP approach for each level in a pairwise comparison. Analyzing those listed factors significance using the AHP approach can then be a starting point for further research as a possible solution for the problem faced by Independent Power Producers (IPP's) to get funding for their Power Purchase Agreement (PPA's). To get a better view of the risks considered by investors in renewable energy projects, formulating the most attractive contract format for domestic investors by using the relative significance of the AHP result. Some previous research conducts around this topic mainly focusses on finding the relative significance of determinants, specifically FDI investment type [1].

Assessing factors that affect investors for their investment decision in renewable energy projects, especially in small-medium scale projects, can be a first step to support new business or start-up developing renewable energy projects. Indonesia, with numerous renewable energy sources, must realize that alternative fossil fuel-based energy exists and could be a nation's best asset in the future.

\section{Literature Review}

\subsection{Investment in the renewable energy sector}

Several studies have examined the field of investment of renewable energy - discussed various topics starting from the financial models, risk involved in all stages of project development until investor motivation to invest in this business opportunity. Project financing research is critical as the renewable energy project usually involves a high level of technology and has a direct impact on the community by contributing to sustainable socioeconomic benefits in new territories [2]. This situation also happens in the development of a renewable energy project in Indonesia.

Financing renewable energy investment involves challenging decision-making processes for many investors because the projects are capital cost-sensitive and combine a fact of a small amount of revenue recognition during its long terms of operation. With those characteristics above, its typical for a firm looking for financial support from outside. Previous research assessed the importance of project finance for renewable energy 
development [3]. Project finance has a much more significant impact on renewables projects than fossil fuel-based power plants in extreme conditions where minimum risk is involved.

Investment models in this industry usually relying on usage of market-based incentives and policies until the new frameworks developed nowadays using balance sheets, operating leases, and power purchase agreements [4]. This variability of the financing method had become a subject of research to analyze the correlation between various renewable energy asset portfolios with various financial actors with the firm size and level of risk [5]. It turns out that the investment portfolio is having a dependency on the type of financial actor behind it as it will dictate the direction of investment decisions.

For many developing countries, foreign direct investment is the primary source of funding and become an effective way to get transfer technology between parties involved. The growing demand for clean energy to reduce climate change is a critical factor in foreign investment for many developing countries, especially for nations with many natural resources for developing renewable energy. Wind and solar energy, as per data, are two primary energy sources attracting the majority of investment worldwide. The development of both sectors could become the catalyst for competition in the electricity market and results in the transitions from fossil fuel-based to renewable energy-based even faster.

Domestic investment, such as venture capital, has proven to become the catalyst in the economy and acts as the new driver of industrial growth sources for one nation. Some factors that influence the investment of venture capital are the status of economic development, the condition of trade policies, level of technology ownership, the degree of community innovation, the entrepreneurship availability, the labor availability, human resources quality, corporate ownership regulations, the legal system, and the business culture. Venture capital is a capital fund that is collected and utilized professionally as a source of finance to private firms. Another type of funding proposed is using several types of bonds, one proposed hybrid bond that can support not only initial cost capital but also the risk associated in some stage of project development. This element led to the ability to cover uncertainties in the investment. Further studies also conduct in the field of investor perspective regarding barriers and policies to capture additional information on why investors prefer some policies over others in the international investor community [6].

\subsection{Previous research}

A specific and dedicated topic of factors or determinants in Energy business especially related to domestic investment in renewable energy, is still limited in numbers. To anticipate this condition, writers are doing a benchmark with the previous research using foreign direct investment types of determinants. The result of this benchmarking will then become the basic framework for tested in the expert interview.

Eyraud et al. [7], in their research, examine determinants of investment in greenfield projects (both in domestic and foreign direct investment). The investigation infers that lowinterest rates or fees, economic growth, high fuel costs, and strategy intervention of policy, including financial support approaches, such as feed-in tariffs, have a positive effect on green investment. The feed-in tariff is a strategy device applied in different nations and encourages the fast spread of renewable energy development. This system offers a guaranteed price for power created by the independent power producers with a commitment of power purchase agreement by the buyer for a fixed long-term period of contracts running from 10 to 20 years. Reports by Ang [8] give empirical confirmations on the effects of different renewable energy policy arrangements on an econometric examination. The study showed that the feed-in tariff framework had a significant effect on increasing investment. However, local content policy in several countries is giving the opposite effect of the investment. 
There is also research focusing on policy affecting renewable energy projects like research by Menanteau et al. [9] found that the overall effectiveness of the economic support policy can affect the investment number. They tried to compare several policies, including feed-in tariff, national energy target, competitive bidding policy, renewable energy trading policy in the research continued by making a comparison of hypothetical cost-based vs. quantity-based approach - the result than compared with an investigation of the actual impact of the policies in several European countries. The examination demonstrates that a feed-in tariff framework is more proficient than a competitive bidding policy. Murovec [10] looked at the determinants of environmental ventures (counting speculations into a renewable power source) utilizing the structural equation model system and found that financial incentives, tax policy, and regulation are critical factors for the investment. Keeley and Ikeda [11] like Murovec using the basic structural equation model to examine the determinant of FDI in wind energy in developed countries. They find sustainable power source policy functioning as robust determinants and explain that mainly administrative support policy (such as guaranteed access to the grid) has a substantial impact on investment decisions.

Another research on the policy effect made by Romano et al. [12] exploring the effectiveness of sustainable energy policy took 56 nations with various social, political, and financial attributes as data sources. The government enacted the policy into administrative arrangements, fiscal incentives, and public investments. Their effects on sustainable energy are examined using econometric examination, showing that not all policies encourage investment in sustainable energy development. The effectiveness of the policy also depends on how the country's development condition. These examinations empirically show that renewable support policies, especially economic support policies such as feed-in tariffs and regulatory support policies such as guaranteed access to the grid, hold substantial importance on renewable energy development investment decisions.

Another view of renewable energy investment observes the barrier for investment decision making. Research made by Painuly [13] builds up an investigation framework for distinguishing boundaries to renewable energy entrance and proposes measures to solve them. It classifies broad ranges of barriers to the dissemination of sustainable energy into market failure/imperfection, market distortions, economic and financial, institutional, technical, social, cultural, and behavioral categories. The determinants of investment include the absence of access to capital, the absence of a legitimate/administrative system, the unstable macro-economic condition, the absence of standard and codes and certification, the absence of social acceptance, the absence of infrastructure, and uncertainty of governmental/legislative policies. Jones [14] explores how investors see barriers to renewable energy infrastructure investment using semi-organized interviews and several open discussions, identifying policy strategy certainty, administration in nations, and limitations in support infrastructure, including transport and access to grid as substantial barriers. Another research observes investment barriers made by Pîrlogea [15], specifically in Romania. Barriers are classifying into organizational, technical innovation, market, and financial barriers. A portion of the significant barriers identified through the survey consists of Approval and permits problem, corrupt act and absence of transparency, access to the existing distribution grid, and high initial Capex.

There also some studies about various types of renewable energy strategies based on the case study in several countries. For example, Abdmouleh et al. [16] found that feed-in tariff, auction process, access to existing grid, countries' energy target, and countries' renewable energy roadmap plan have demonstrated effective dissemination of renewable energy. Auction is a call for competitive offering from some independent power producers for renewable energy power generation under long term power purchase agreement. Countries' renewable energy development plan shows how one country set up its mid to extended strategic plan to increase the percentage of renewable energy usage in its national energy 
plan. Concerning economic support policies, the study gives a firm but a supportive argument about the feed-in tariff issue. The initial value of the tariff is usually hard to determine by the regulator. To reduce the risk of failure of feed-in tariffs, they propose to focus on a competitive bidding system as the benchmark criteria before applying a feed-in tariff system. They were also highlighting the significance of reliable political support in every stage from national, provincial, and neighborhood levels through smooth bureaucratic application methodology, target setting, and process monitoring.

Zeng et al. [17] made research specifically look after issues in financial aspects and solutions of renewable energy development in BRICS nations. The examination declares that the absence of financing facility and investment shortage in small and medium-sized power producers obstruct the improvement of developing renewable energy facilities in these nations. They mention that the financial market is necessary to let this industry grow as they found that renewable energy is still perceived as a risky investment due to long-term business uncertainty in developing countries. This finding leads to the fact that many commercial banks are not confident enough to allocate their credit funds to the sector with low-interest rates.

\subsection{Importance factor for Investment Decision Making}

The main regulatory framework for investment in the power generation industry in Indonesia is the decree No. 25, the year 2007 about investment. It is describing major principles related to the establishment and how to conduct operations to support business activities. The most recent specific study on the Indonesia market is talking about factors that can attract investors on the rural village grid using revenue stream type as an indicator. It mentioned that private investors could address many barriers of investment with the interference on reducing the risk involved [18].

Numbers of Study about factors influencing investor decisions in Indonesia are presumably rare. Research conduct by Keeley et.al. [1] using literature review and series of interviews, mainly focused on FDI type and limited to big development projects of wind and solar energy, resulted in frameworks contain a list of factors of investor perspective used to make an investment decision. A report published by the relevant agency showed that Indonesia could not meet the 2019 renewable energy target of $16 \%$ primary energy mixed and $17.5 \%$ of total capacity [19]. The majority of those investments are on the big project of geothermal energy, which related to FDI type of investment. Failure to achieve renewable energy targets also related to the phenomenon during the 2017-2018 power purchase agreement problem. About 27 power purchase agreements (PPA's) from a total of 75 PPA's are unable to get the financial closure stage - even they have purchasing agreements from the national power company. Mainly of them are small-medium size companies in the minihydro project.

Based on previous research and recent reports, we can see the importance of improving the numbers of renewable energy investments to get the targeted energy mixed and further reduce the dependency of importing fossil fuel commodities. The research can be starting by understanding the factor affecting domestic investor decisions on making their investment. This research will carefully assess the factors influencing renewable energy projects to get financial closure, analyze the significance of each factor using the Analytic Hierarchy Process (AHP). 


\section{Research Methodology}

This study aims to assess factors influencing investors for their investment decision in a renewable energy project, especially in the small-medium scale of the project. One aspect that critical and crucial for having the identification of the barriers for the investor is observed by Painuly [13]. The interaction with practitioners in the field through structured interviews and questionnaires can be the source of the valuables not only to know the barriers from the investor perspective but also to understand better how to overcome the barriers itself.

\subsection{Source of data}

To capture all information from the expert about the investment of renewable energy projects and to verify the factors that shape investor perspective, this study uses literature review and semi-structured interviews as the first stage data collection. This study collects all factors that need to use in the AHP hierarchy process in that stage. The result of the expert interview then becomes a questionnaire for further tests using various expert backgrounds to get a broader point of view, which can show the importance of each factor in the development of renewable energy in Indonesia. According to a study by Kuhnert et.al. [20], the expert classification is people knowing intensive study, practice, and have some experiences. Table 1 shows the list of respondents in this study.

A descriptive research study is conducting in the research process using the analytic hierarchy process (AHP) concept to explore and identify critical determinants influencing domestic investment decisions in Indonesia's renewable project development. For conducting the AHP process, we create a hierarchy with broad categories at first, continued to the subcategories until, finally, the determinants we got from the literature review. We must not forget the theme of the analysis, which placed at the top of the hierarchy.

\subsection{Analytic Hierarchy Process}

In AHP, as we described before, we must structure a problem in a hierarchical model by considering various levels of parameters to achieve the goal needed. A hierarchy is usually large enough to capture our significant concerns in the research and small enough to remain sensitive to change in what is essential. In this study, the draft of the hierarchy shown in figure 1 . 


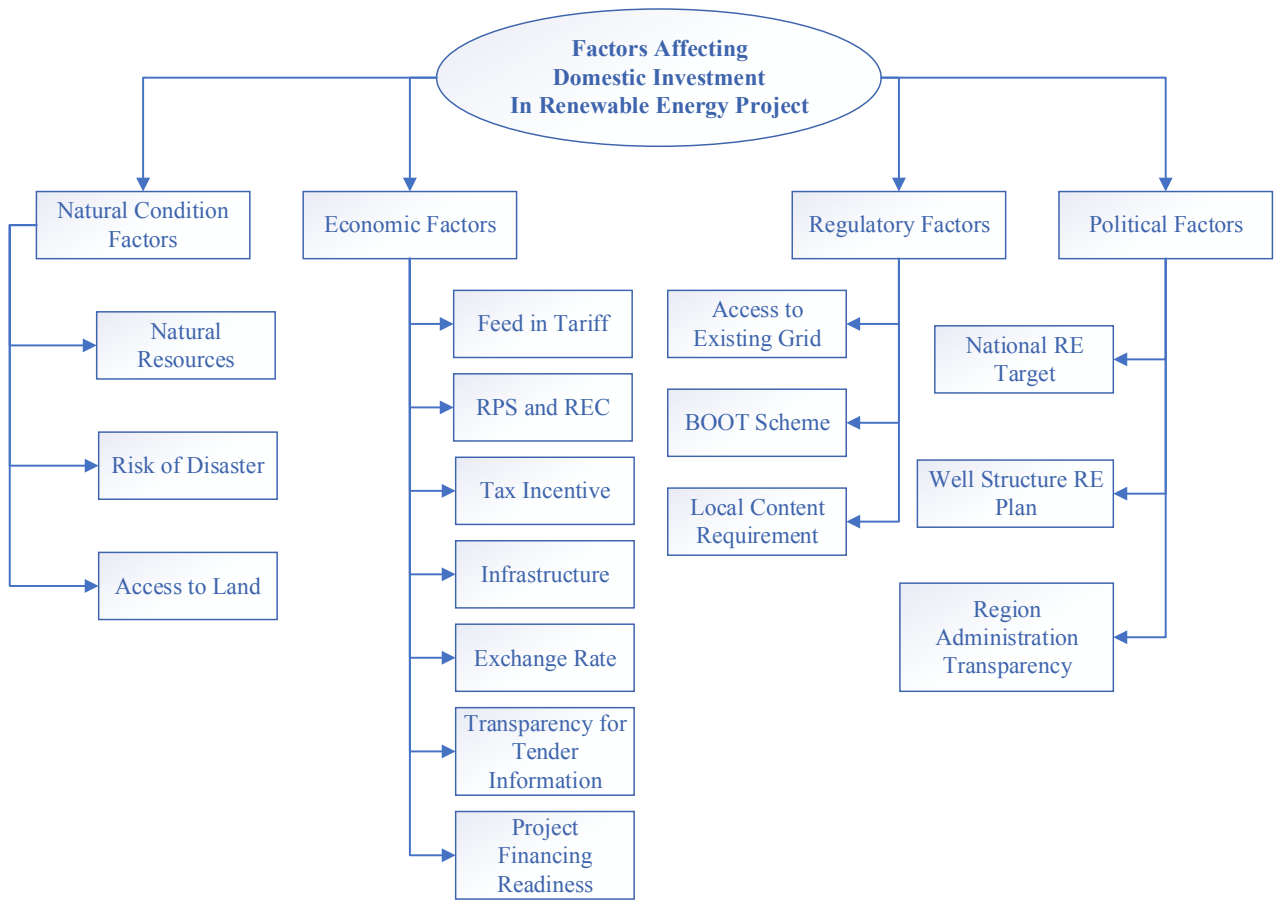

Fig. 1. Hierarchy Model tested on AHP.

Table 1. Respondents Profile.

\begin{tabular}{|c|c|c|}
\hline No & Institution - Sector & Position \\
\hline Respondent 1 & $\begin{array}{l}\text { NGO - Climate \& Finance } \\
\text { Policy }\end{array}$ & Analyst \\
\hline Respondent 2 & Start-Up - Renewable & Founder \\
\hline Respondent 3 & $\begin{array}{l}\text { State-Owned Company - } \\
\text { Energy }\end{array}$ & $\begin{array}{l}\text { Sr. Procurement / } \\
\text { Tender Committee }\end{array}$ \\
\hline Respondent 4 & $\begin{array}{l}\text { Private Company } \\
\text { Renewable Energy }\end{array}$ & $\begin{array}{l}\text { Project Development } \\
\text { Manager }\end{array}$ \\
\hline Respondent 5 & Financing Company & Project Development \\
\hline Respondent 6 & $\begin{array}{l}\text { Private Company } \\
\text { Renewable Energy }\end{array}$ & Market Development \\
\hline Respondent 7 & $\begin{array}{l}\text { Private Company } \\
\text { Renewable Energy }\end{array}$ & $\begin{array}{l}\text { Sr. Business } \\
\text { Development }\end{array}$ \\
\hline Respondent 8 & $\begin{array}{l}\text { Private Company } \\
\text { Renewable Energy }\end{array}$ & Market Development \\
\hline Respondent 9 & $\begin{array}{l}\text { Private Company } \\
\text { Renewable Energy }\end{array}$ & Country Head \\
\hline Respondent 10 & $\begin{array}{l}\text { State-Owned Company - } \\
\text { Financing }\end{array}$ & Project Development \\
\hline Respondent 11 & $\begin{array}{l}\text { Private Company } \\
\text { Renewable Energy }\end{array}$ & Business Development \\
\hline Respondent 12 & Private Company - Energy & $\begin{array}{l}\text { GM Business } \\
\text { Development }\end{array}$ \\
\hline Respondent 13 & Financing Company & Analyst \\
\hline
\end{tabular}


The next stage of the research is setting priorities among the criteria or determinants that identified before in general. This priority setting will give affected the result of the questionnaire we gave to the respondent. AHP then used to finalize the prioritization process to find the significance of a set of each factor and sub-factors shown in the hierarchy. From the literature review, the majority of topics of deployment AHP on cases related to renewable energy is to find out the best renewable energy technology to deploy in a particular region or environment. There are still limited cases showing the application of AHP to examine the financial topic related to domestic investor investment decisions. This issue can be an originality point of this paper.

Table 2. Saaty's scale for AHP.

\begin{tabular}{cll}
\hline $\begin{array}{c}\text { Level of } \\
\text { Importance }\end{array}$ & Definition & Explanation \\
\hline 1 & Equal Importance & Two factors contribute equally \\
3 & Somewhat more important & $\begin{array}{l}\text { Experience and judgment slightly } \\
\text { favor one over the other } \\
\text { Experience and judgment strongly } \\
\text { favor one over the other } \\
\text { Experience and judgment strongly } \\
\text { favor one over the other. Its } \\
\text { importance is demonstrated in } \\
\text { practice. } \\
\text { The evidence favoring one over the } \\
\text { other is of the highest possible } \\
\text { validity. } \\
\text { When compromise needed }\end{array}$ \\
& Very much more important \\
$2,4,6,8$ & More important & Intermediate values
\end{tabular}

We then need to evaluate factors in the hierarchy by comparing one factor to another at a time. To find the influence of factors in the hierarchy, we can use the 1-9 scale proposed by Saaty [21]. We can see a description of this scale in table-2. The next step is to evaluate and converting the result to numerical values for further data processes. We then need to make a pairwise judgment, then continue converting it to the pairwise matrix. After we raise a pairwise matrix, we will need to gain a normalized matrix and calculate the eigenvector to represent the importance's weight.

The consistency level of each pairwise comparison matrix is checked as the justification for evaluation feedback. We can use a formula named consistency index (CI) and the consistency ratio (CR). The Consistency index can be calculated based on the following equation one (1) proposed by Saaty [21]:

$$
C I=\frac{\lambda \max -n}{n-1}
$$

(n) represent the number of evaluating factors, and ( $\lambda$ max) represent the maximum eigenvalue of the matrix. The Consistency Ratio is defined in equation 2:

$$
C R=\frac{C I}{R I}
$$

(RI) represent the average value of the CI from n Number positive reciprocal pairwise comparison matrices about entries were randomly generated using the 1-9 scale described in table 2 . 
Meanwhile, Table 3 provides RI range values for different $\mathrm{n}$ number.

Table 3. Values of the random index for different matrix order.

\begin{tabular}{lcccccc}
\hline \multicolumn{7}{l}{ Relationship between $\mathbf{n}$ and RI } \\
$\mathrm{n}$ & $1-2$ & 3 & 4 & 5 & 6 & 7 \\
$\mathrm{RI}$ & 0 & 0.58 & 0.9 & 1.12 & 1.24 & 1.32 \\
\hline
\end{tabular}

It is essential to pay attention to the $\mathrm{CR}$ value. If $\mathrm{CR}$ is equal to 0 , then we can take the respondent's answers entirely consistent; If $\mathrm{CR}$ is equal to 1 , then the answers are entirely inconsistent.

In general, based on Thomas Saaty's theory, we can interpret answers within the range of $0.1-0.15$ are considered consistent enough to be acceptable [21]. Under the condition of CR value above 0.15 , it is recommended to repeat evaluation until we get acceptable consistency. However, in real AHP practice, a comparison matrix usually gives weak consistency, so repeating the evaluation until getting acceptable consistency can be difficult. In this study from 20 questionnaire responses, only 13 responses are valid for CR value under 0.1 and will be used in further result and analysis.

Next, usage of the eigenvector method, we then make a pairwise comparison with a high level of consistency value to make a combined consolidated decision matrix to obtain the result. The weighted geometric mean of the decision matrix factors, which is expressed as the following equation 3 :

$$
C_{i j}=\exp \frac{\sum_{k=1}^{n} \omega k \operatorname{In} a_{i j(k)}}{\sum_{k=1}^{n} \omega k}
$$

Where " $\mathrm{C}$ " is the consolidated decision matrix and " $\mathrm{k}$ " as the number of participants' inputs to obtain the aggregated group result [22], after going through all processes, we can generate a numerical weight act as relative significance to be derived for each factor. This technique allows the factors to be compared with one another consistently and rationally. Then, we calculate the consensus ratio among the respondents using the Shannon alpha and beta entropy. The consensus indicator ranges from $0 \%$ (no consensus between experts) to $100 \%$. The AHP consensus ratio "S" calculated using the following equation 4 :

$$
\begin{gathered}
S=\frac{M-\exp \left(H_{\propto \min }\right)}{\exp \left(H_{\gamma \max }\right)} / \frac{1-\exp \left(H_{\propto \min }\right)}{\exp \left(H_{\gamma \max }\right)} \\
\text { with } M=\frac{1}{\exp \left(H_{\beta}\right)}
\end{gathered}
$$

The responses accumulated from the questioner and empirical study will then be analyzed using the Analytic Hierarchy Process to assess the dominant parameter and correlation of each parameter involved in the decision to develop renewable projects.

\section{Result and discussion}

Results from AHP calculation are divided into five sections consist of evaluation on general factors affecting domestic investment, the political situation, regulation, natural condition, and economic factors. The results are produced using Goepel [22] spreadsheet and using parameter mention in the previous section. Percentage result from first stage comparison in section 4.1 multiplied by percentage result on each evaluation of the derivatives is overall factors combination shown in figure 7. 


\subsection{First stage evaluation on general factors affecting domestic investment}

In this first stage evaluation, the respondents asked to choose their preferences on four major categories: Politic, Economic, Regulation, and Natural condition. Those four factors were chosen as the general factors based on interviews with the expert and literature review on a previous study by Keeley [1] on the relative significance of determinants on Foreign Direct Investment for Wind and Solar Energy.

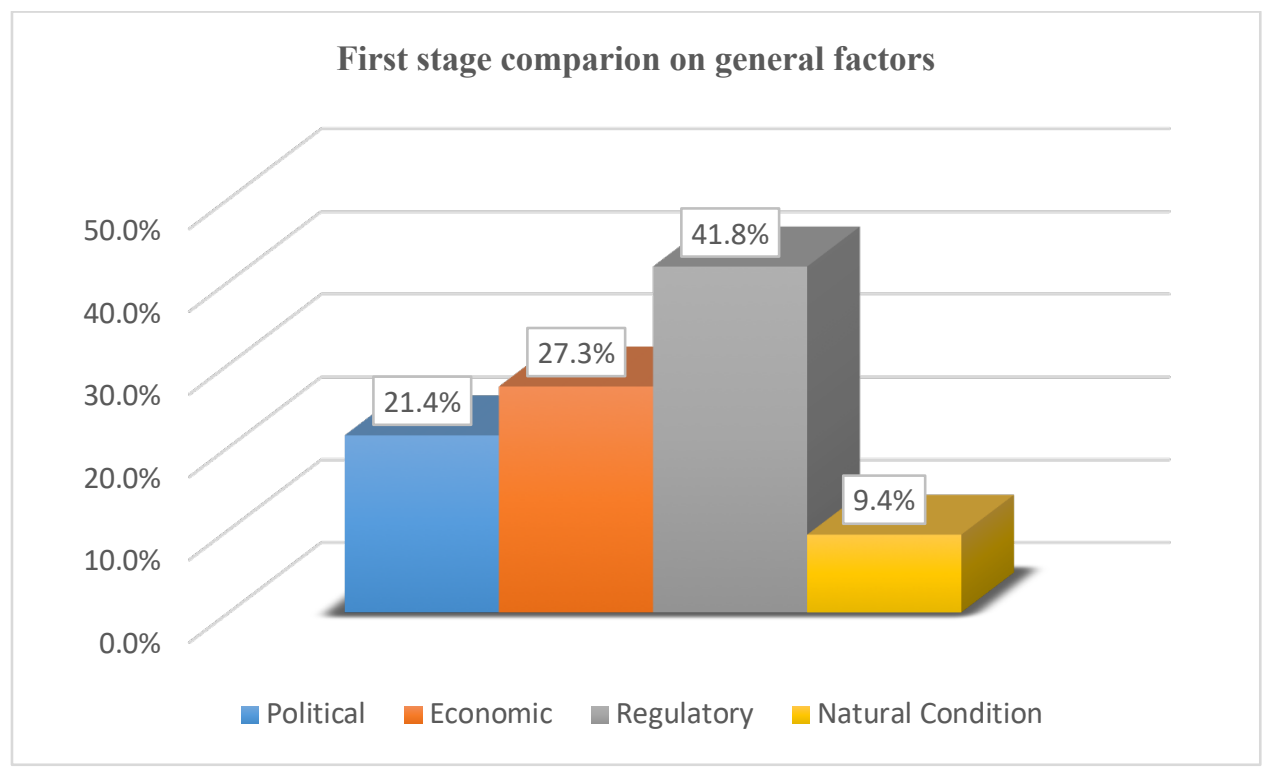

Fig. 2. The priority of each factor on $1^{\text {s }}$ level comparison.

From the respondent's feedback, the regulation factor refers to any regulations that support renewable energy, such as access to the existing grid, BOOT or BOO scheme, and local content requirement. It is showing to have the most critical factor for the investor to spend their resources in developing a renewable energy project. It reaches $41.8 \%$ followed respectively by Economic factors which including any economic support for renewable energy, such as feed-in tariff, renewable energy certificates, and renewable portfolio standards, tender information, tax-incentives, and project financing readiness. This economic factor perceived $27.3 \%$ from respondent feedback. Political factor and Natural Condition follow with $21.4 \%$ and $9.4 \%$, respectively, as shown in Figure 2. The consensus ratio calculated by $50 \%$, which categories as low consensus, but the consistency ratio found less than 0.1 as the maximum value.

\subsection{Evaluation of natural condition factor}

Figure 3 presents the result of the evaluation of the natural condition factor. This testing involved three main factors: natural resources explaining solar resources potential, insolation/sunshine duration, and water supply. The risk of disaster represents the risk involved in the project in the form of potential natural disasters such as landslide and earthquakes. Access to land represents stable and reliable access to the land of the project site and land utilization as the production area. 


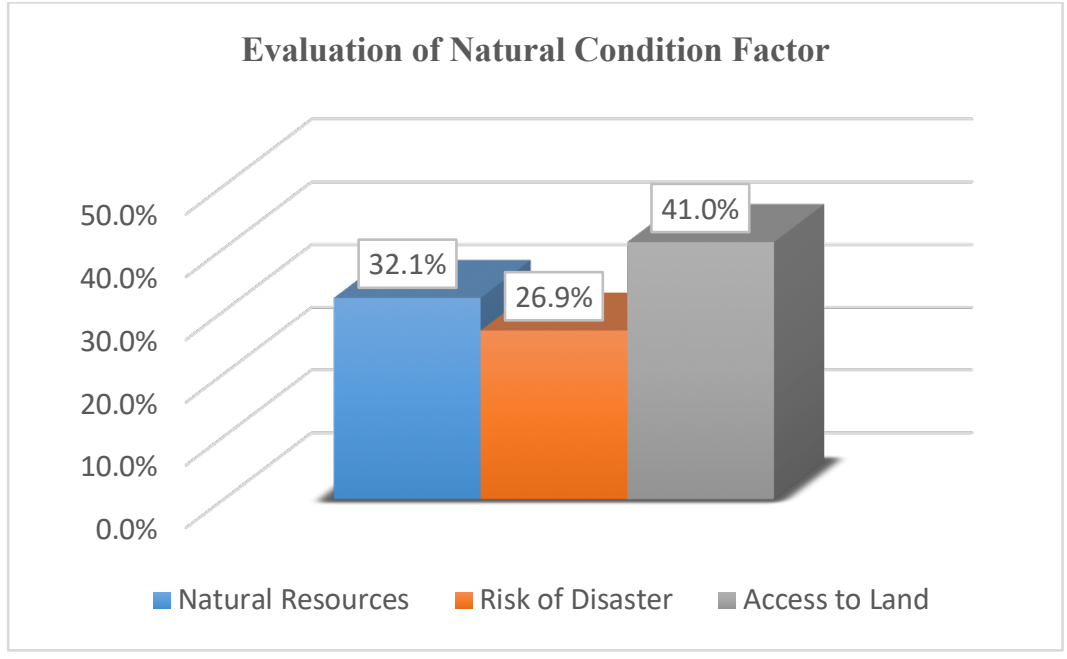

Fig. 3. The priority of natural condition factors.

From respondent feedback, access to land becomes the most critical factor in respondent perspective with $41 \%$. The utilization of land for power generation and power distribution needs a special permit from the government and related to the fact that Indonesia rules the state-owned enterprise is getting a particular task to control electricity business in the country. Natural resources $(32.1 \%)$ become another important factor for the renewable energy business. Indonesia, positioned in the equator area, had excessive solar potential. Moreover, as a ring of the fire nation, Indonesia has enormous potential for geothermal, so the respondents' perception of this level of importance can be seen while making their judgment. Risk of disaster calculated into a $26.9 \%$ importance level by the respondent source from the fact that Indonesia is having risk for natural disasters due to geographical location. The consensus ratio calculated $39 \%$, which is meager means there is a vast difference from each respondent's view of the tested factor. The consistency ratio observed less than 0.1 .

\subsection{Evaluation of regulatory factor}

As presented in figure 4, the evaluation of the regulatory factor resulted in the Access grid become the most critical factor in this category, with $43.7 \%$. All independent power producers are set to sell their electricity to the PLN as the state-owned enterprises for electrical business under the power purchase agreement. Chance to sell electricity directly to consumers relatively rare and need PLN to release their works area concession before the government can release it for a private company. The next important factor in this category is the local content factor. This fact happens because many critical components of technology still need to be imported; any changes in local content policy can be a game-changer even for big independent power producers. The last factor observed in this category is the BOOT Scheme. There is a BOOT scheme applied under ministerial regulation No. 53/2018, which gives investors an obligation to transfer their renewable energy project to the PLN after the power purchase agreement comes to an expired period. The scheme is not popular amongst IPP companies, especially for the small-medium scale company. It can discourage creditors from financing projects as they cannot accept the projects as collateral for the loans. The revoke action on this policy can be the best move to boost a renewable project's bankability. Consensus ration for this evaluation is calculated $32 \%$ classified as very low, with the consistency index below 0.1 . 


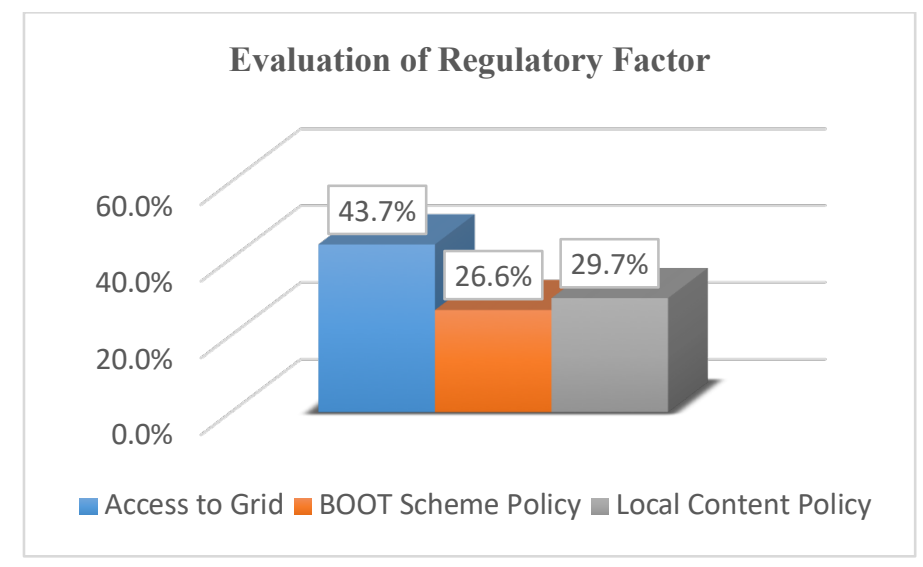

Fig. 4. The priority of regulatory factors.

\subsection{Evaluation of political factor}

The evaluation of political factors related to domestic investment showing the transparency of process administration is by far the most crucial determinant among the political factors, with a weight of $50.2 \%$ shown in figure 5 .

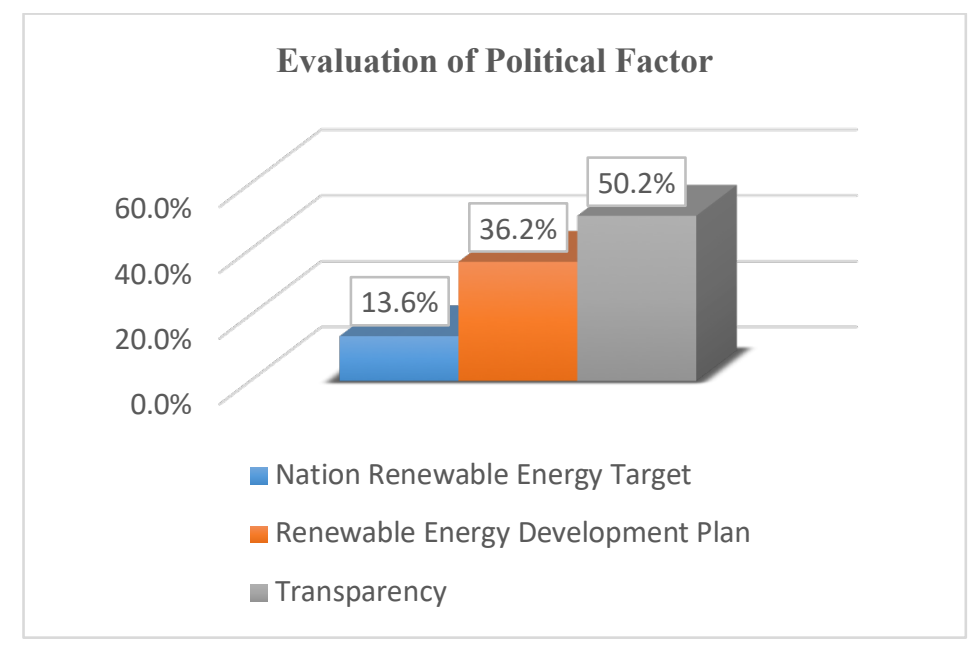

Fig. 5. The priority of political factors.

Transparency on the administration not only crucial for investors as it might be related to all permits and guidance on how they can make their investment sustain in the long run. The national renewable energy development plan and nation renewable energy target is placed after the transparency with weight $36.2 \%$ and $13.6 \%$, respectively. The consensus ratio is $53 \%$ classified as low consensus and the consistency index below 0.1 .

\subsection{Evaluation of economic factor}

The results for the evaluation of the importance level of the economic factors are presented in figure 6. Feed-in Tariff(FIT), as the most common and frequently used policy in a country with renewable energy development agendas, is shown to be the most influential factor 
among the economic category, with a weight of $21 \%$. The next most influential factor is project financing with $20.3 \%$ and tender clarity with $18.6 \%$. Both factors are also mentioned by the expert in the questionnaire comments box as the crucial factor related to the bankability issue, especially for the small-medium scale independent power producers. The consensus ratio is $49 \%$ classified as low consensus and the consistency index below 0.1 .

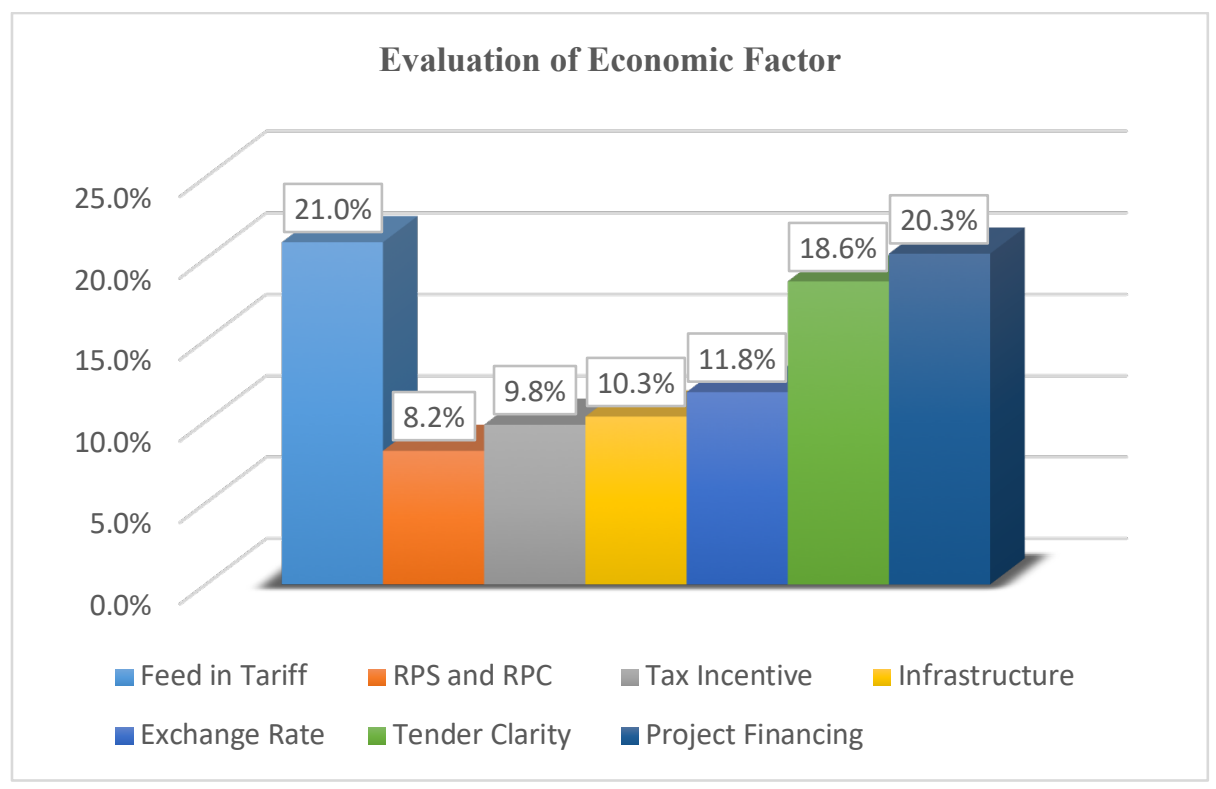

Fig. 6. The priority of economic factors.

Based on the questionnaire's feedback of 13 experts active in developing renewable energy in Indonesia, Factors affecting domestic investment with their level of importance can be clarified. By multiplying each determinant's weight by the weight of the determinant's category, the level of importance of each factor is calculated. Figure 7 shows the results for all the factors.

Access to the grid factor has the highest level of importance $(18.3 \%)$. Transparency $(10.7 \%)$ and Feed-in Tariff $(5.7 \%)$ are followed in the second and third places. Three of those factors are the top three factors identified by respondents in this research. The access to the grid is crucial due to the market condition where PLN fully controls all power distribution as the government-owned company for electricity business. It means that all independent power producers must have a contract in the form of the power purchase agreement to distribute their electricity. In some cases, there are some exceptions to this. PLN agreed to release their right of area concession to be used directly by independent power producers - mainly in a high-dense industrial complex. With the condition above where some companies control the market, we can see competition mainly occurred in the independent power producer itself to get the PPA contract. In the long run, this condition can cause many small-medium scale IPP to sacrifice the quality of project assessment and their project feasibility studies report. Later, it will not become attractive for getting project funding.

The second factor identified as administration transparency is getting the transparency on project clarity is critical for IPP. Getting a clear picture of the project needed and how it can be appropriately executed is vital to let IPP provide the best proposal to the prospective investor. 
The third factor is about Feed-in Tariff, by having FIT pricing policy which allowed guarantee fixed electricity price the power producer will be able to get financial return certainty and relatively more straightforward to forecast their project cash flow. Improving project attractiveness will significantly boost investor appetite.

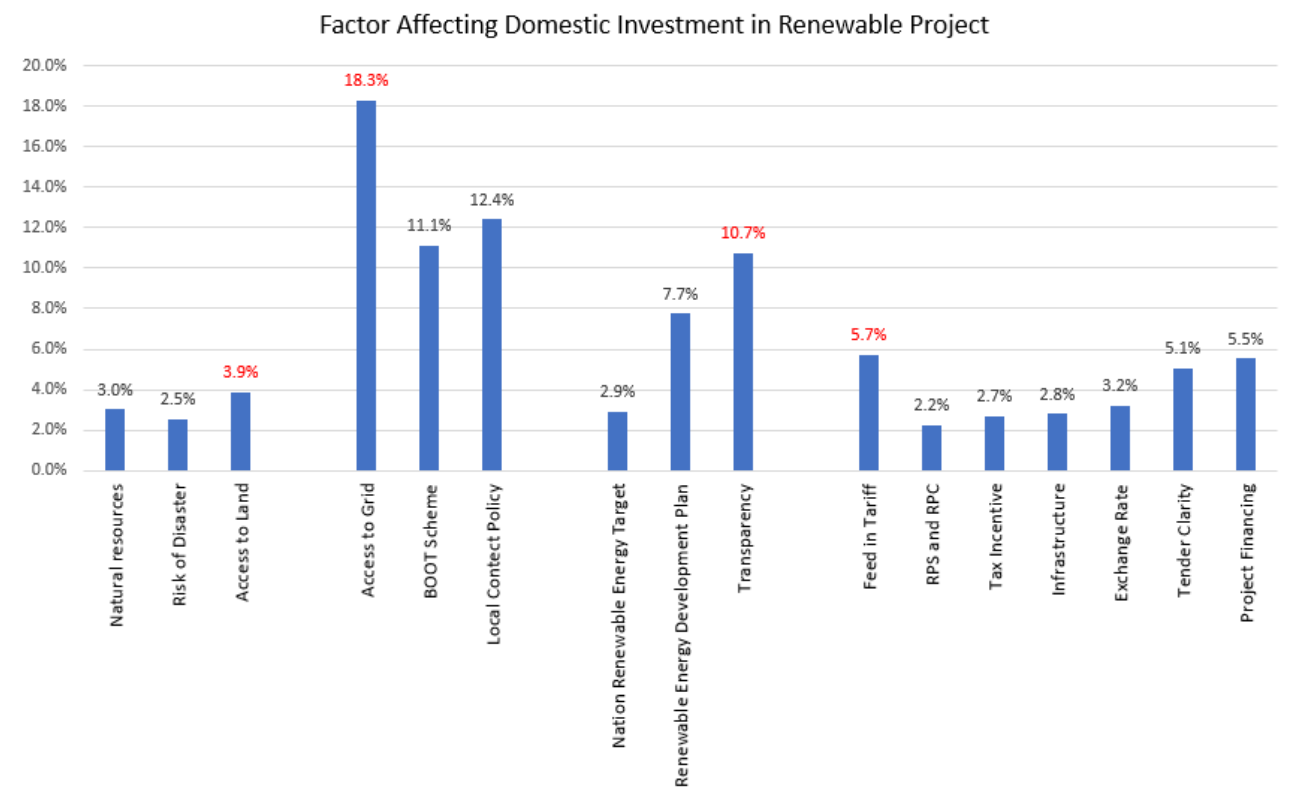

Fig. 7. The priority of all factors combined

Some actions are needed as a breakthrough to reach the energy mix target (See figure 7). Existing regulations indicate that Indonesia should have reached a 17.5 percent renewable energy mix by 2019 , yet the country only reach 12.36 percent. Revoke ministerial regulation No. 53/2018 about BOOT combined with tender transparency and competitive Feed-in Tariff can be a starting point. Then, assessing carefully about letting private company have direct access to consumers as long-term action since opening the electricity market for the competition are related to the primary national interest.

\section{Conclusion and Future Studies}

This study's objective is to identify any possible factors considered by domestic investors to support the development of renewable energy in Indonesia. By the end of this research, we can get a picture of the list of important factors perceived by investors for developing renewable energy projects. This research showed that the domestic investors perceived access to the grid is crucial due to the market condition where the state-owned company fully controls all power distribution for the electricity business. It means that all independent power producers must have a contract in the form of the power purchase agreement to be able to distribute their electricity. The transparency on project clarity also critical for IPP. By getting a clear picture of the project needed and how it can be appropriately executed are important to let IPP provide the best proposal to the prospective investor. The last most crucial factor has FIT pricing policy, which allowed guarantee fixed electricity price the power producer will be able to get financial return certainty and relatively more comfortable to forecast their project cash flow. 
Attracting foreign direct investment will need extra effort from all stakeholders in the country. So, the domestic investor can play a part to start involving the development of a new start-up in this industry. Indonesia has a huge potential source of renewable energy and will always be an attractive market for investors. With the trend in the future of the electric car, The Presidential Regulation No. 55/2019 provides a clear support regulation for electric vehicles. This regulation opens the opportunity to introduce more electric vehicles. This situation is a business opportunity for Indonesia start-up to provide not only the technology of the automotive itself but also the complete ecosystem for it, such as public charging points and service center for supporting the new ecosystem. Nonetheless, understanding investor perception is crucial in the process of establishing a sustainable renewable energy development project. Factors identified in this paper can be an example of how we can develop a better investment climate, so their perception of Indonesia can be shifted, regain the trust of investors and slowly remove barriers that hamper renewable energy deployment in Indonesia.

The results provide some insights for the regulatory body, especially those related to power generation sectors, to develop some policies. rThe introduction of feed-in-tariff policy by the government is a must-do thing to stimulate investor perception; having this policy in place can be a way to attract investors. Moreover, the government prepares to implement the reverse auction method for the future development of renewables projects. Transparency on government plans and timetables must be announced so investor expectations can be managed in better ways. For the renewable industry, the government must be aware that Indonesia competes with its neighboring countries in the region to attract investments in renewable energy. To attract foreign direct investment and domestic investment, the government needs to have a better energy efficiency policy with broader coverage of energy consumers required to have energy management systems.

This research comes with some limitations that can be subject to future studies. In real practice, with many variables tested, a comparison matrix often has weak consistency, repeating the evaluation numerous times is practically difficult. This practice will lead to better quality feedback from the respondent. By allowing the same respondent with CR greater than $10 \%$ retaking the questionnaire, we can reduce the bias source from the respondent's subjective point of view. Another further study should focus on topics of the Feed-in Tariff effect to PLN Generation cost. This topic should also be considered as the application of this Feed-in Tariff scheme can increase PLN's generation cost, and support mechanisms should be prepared.

\section{References}

1. A. Keeley, K. Matsumoto, Investors' perspective on determinants of foreign direct investment in wind and solar energy in developing economies - Review and expert Opinion, in Journal of Cleaner Production (2017)

2. D. Rio, M. Burguillo, An empirical analysis of the impact of renewable energy deployment on local sustainability, in Renewable and Sustainable Energy Reviews, 1314-1325 (2009)

3. B. Steffen, The importance of project finance for renewable energy projects, in Energy Economics Journal (2017)

4. C. Wing Lee, J. Zhong, Financing and risk management of renewable energy projects with a Hybrid Bond, in Renewable energy journal, 75, 779-787 (2014)

5. M. Mazzucato, G. Semieniuk, Financing renewable energy: Who is financing what and why it matters. In Technological Forecasting \& Social Change journal 127, 8-22 (2017) 
6. M. Burer, R. Wustenhagen, Which renewable energy policy is a venture capitalist's best friend evidence from a survey of international cleantech investors, in Energy Policy, 37(12), 4997-5006 (2009)

7. L. Eyraud, B. Clements, A. Wane, Green investment : Trends and Determinants, in Energy Policy Journal, 60, 852-865 (2013)

8. G. Ang, Overcoming barriers to international investment in clean energy, in www.oecdilibrary.org (2016)

9. P. Menanteau, D. Finon, M. Lamy, Prices versus quantities:choosing policies for promoting the development of renewable energy, in Energy Policy Journal, 31, 799-812, (2003)

10. N. Murovec, R. Erker I. Prodan, Determinants of environmental investments: testing the structural model, in Journal of Cleaner Production, 37, 265-277, (2012)

11. A. Keeley, Y. Ikeda, Determinants of foreign direct investment in wind energy in developing countries, in Clean Production Journal, 161, 1451-1458, (2017)

12. A. Romano, G. Scandurra, G, A. Carfora, M. Fodor, Renewable investments : the impact of green policies in developing and developed countries, in Renewable Sustainable Energy, 68, 738-747, (2017)

13. J. Painuly, Barriers to renewable energy penetration; a framework for analysis, In renewable energy journal, 24(1), 73-89, (2001)

14. A. Jones, Perceived barriers and policy solutions in clean energy infrastructure investment. In Journal of Cleaner Production, 104, 297-304, (2015)

15. C. Pîrlogea, Barriers to investment in energy from renewable sources, In Econ. Ser. Manag, 14, 132-140, (2011)

16. Z. Abdmouleh, R. Alammari, A. Gastli, Review of policies encouraging renewable energy integration \& best practices, In Renewable and Sustainable Energy Reviews, 45, 249-262, (2015)

17. S. Zeng, S., Y. Liu, C. Liu, X. Nan, A review of renewable energy investment in the BRICS countries: History, models, problems and solutions. Renewable and Sustainable Energy Reviews, 74, 860-872, (2017)

18. T. Schmidt, N. Blum, R. Wakeling, Attracting private investments into rural electrification-A case study on renewable energy based village grids in Indonesia, In Energy for Sustainable Development, 17(6), 581-595, (2013)

19. M. Guenther, "A $100 \%$ Renewable Energy Scenario for the Java-Bali Grid," International Journal of Renewable Energy Development, vol. 7, no. 1, pp. 13-22, (2018)

20. P. Kuhnert, T. Martin, S. Griffiths, A guide to eliciting and using expert knowledge in Bayesian ecological models. In Ecology letters, 13(7), 900-914. (2010)

21. T. Saaty, The Analytic Hierarchy Process: Planning, Priority Setting, Resource Allocation, (1980)

22. K. Goepel, Implementing the analytic hierarchy process as a standard method for multicriteria decision making in corporate enterprises-a new AHP excel template with multiple inputs. In Proceedings of the international symposium on the analytic hierarchy process, p1-10 (2013) 